\title{
Numerical Investigation of Residual Stresses in Chain-die Formed AHSS U-Channels
}

\author{
Yong Sun ${ }^{1,}$, Zhen Qian ${ }^{1, b}$, Vladimir Luzin ${ }^{1, \mathrm{c}}$, William J.T Daniel ${ }^{1, \mathrm{~d}}$, \\ Mingxing Zhang ${ }^{1, \mathrm{e}}$ and Shichao Ding ${ }^{1, \mathrm{f}^{\star}}$ \\ ${ }^{1}$ School of mechanical and Mining Engineering, The University of Queensland, QLD, Australia \\ ${ }^{2}$ Australian Nuclear Science and Technology Organization, Lucas Heights, NSW, Australia \\ ay.sun@uq.edu.au, bz.qian@uq.edu.au, 'Vladimir.Luzin@ansto.gov.au, dbilld@uq.edu.au, \\ emingxing.zhang@uq.edu.au, 's.ding@uq.edu.au
}

Keywords: Residual Stresses, AHSS, U-Channel, Chain-Die Forming, Finite Element Analysis

\begin{abstract}
Advanced high-strength steel is increasingly being used in automotive structural components due to its excellent strength-to-weight ratios. However, the variations of residual stresses magnitude in AHSS products are usually very complex and unpredictable due to the fabrication process and the material's high strength. Consequently, unbalanced residual stresses are responsible for a series of product defects. Chain-die forming is a novel AHSS fabrication method which has the characteristics of preserving the material's ductility maximally and also reducing the residual stresses in the product. In this study, the finite element method is employed to investigate the equivalent residual stresses (Von Mises) in Chain-die formed AHSS U-channels. Finite element simulation of roll forming of the same type as AHSS U-channel forming is performed to make a comparison of the residual stresses distribution characterizations in AHSS U-channels which are fabricated by roll forming and by Chain-die forming. The results indicate that the residual stresses in Chain-die formed U-channels stay at a very low level and are almost negligible. In the meanwhile, due to the bending, reverse bending and other unpredictable redundant deformation types in the roll forming process, the residual stresses are more significant than those of Chain-die formed AHSS channels. The comparison of the longitudinal strain developments of flange edges of roll formed and Chain-die formed U-channels is given to explain the differences between the residual stress distributions in the roll formed and Chain-die formed U-channels. This paper gives a comprehensive understanding of the characteristics of the residual stress distribution in Chain-die formed AHSS U-channels. It provides a clear evidence to illustrate the superiority of Chain-die forming in reducing the residual stresses in AHSS products.
\end{abstract}

\section{Introduction}

Advanced High-Strength Steel (AHSS), especially dual phase steel, is more and more frequently being employed by automakers for structural parts of a motor vehicle due to its advantages for weight reduction and safety improvement. AHSS has the required high strength but the elongation is not large enough. The characteristics bring more challenges in fabricating AHSS products.

Roll forming is a highly efficient fabricating method for mass production of long and straight metal products. It can be understood as a continuous bending operation which the metal strips are progressively formed through consecutive sets of rolls into various profiles [1]. Although roll forming has been developed over a century, there are still unsolved issues in predictability and control of the redundant plastic deformation occurring during a roll forming process due to relaxation between roll stands [2]. Consequently, this becomes a bottleneck which greatly restricts the development and application of roll forming. Specifically, the non-uniform permanent plastic deformation results in the residual stresses in a roll formed product. The distributions of residual

(c) (1) Content from this work may be used under the terms of the Creative Commons Attribution 3.0 license. Any further distribution of this work must maintain attribution to the author(s) and the title of the work, journal citation and DOI. Published under license by Materials Research Forum LLC. 
stresses are responsible for a series of typical roll formed product defects and/or distortions from the desired product shapes, such as curvature, end flare, edge wave, torsion, springback and so on [3]. It should be also noted that the existence of longitudinal residual stresses would adversely affect structural stability, fatigue performance, stiffness and other properties [4].

Chain-die forming, as a novel sheet metal forming method, was therefore proposed by Ding et al. [5] to break the bottleneck of fabricating AHSS products. It is considered to have a high potential to be a more economical and energy-saving method compared to conventional roll forming, due to its technical characteristics of both bending and stamping. Ding et al. [5] performed a series of experiments of Chain-die forming AHSS U-channels with pre-made holes. They proved that the technology has the advantage of conserving the material's ductility. This shows that Chain-die forming can be used to fabricate AHSS products, even though some of them have poor ductility, as there is almost no redundant plastic deformation and low residual stresses in the non-deformed areas.

As Ding et al. [5] introduced, the principle of Chain-die forming is to prolong the effective forming distance by extending the virtual roll radii. Specifically, the technology introduces a series of discontinuous forming tools moving on a track board to implement the virtual large rolls, as seen in Fig. 1 (a). The increase of deformation length shown as in Fig. 1 (b) results in the reduction of the peak longitudinal strain and the residual longitudinal strain. That is, the large roll radii can significantly reduce or even eliminate the redundant plastic deformation occurring in roll forming. Consequently, the corresponding residual stresses are significant reduced. The typical defects of roll formed products can be therefore theoretically removed, thus improving the quality of products.

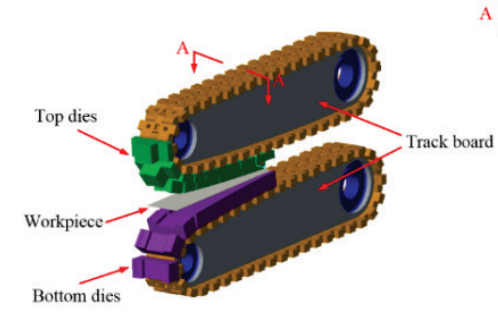

(a) Schematic diagram of Chain-die forming

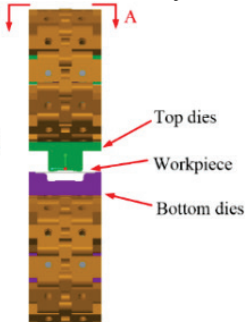

(b) Comparisons of the deformation lengths of roll forming and Chain-die forming

Fig 1.The principle of Chain-die forming. (Note: $R$ are the radii of the top and bottom rolls of Chain-die forming and $R^{\prime}$ is the radius of a roll of conventional roll forming )

The structure of the paper is as follows. A brief background of residual stresses in roll forming and the principles of Chain-die forming are introduced in this section firstly, followed by the clarifications of finite element (FE) modeling of roll forming and Chain-die forming AHSS Uchannels. Then the equivalent residual stresses (Von-Mises) in the non-deformation areas of roll formed and Chain-die formed AHSS U-channels are investigated. The comparison of the longitudinal strain developments of the flange edges of roll formed and Chain-die formed AHSS U-channels are then studied and discussed. Finally, some important concluding remarks are summarized.

\section{FE modeling}

The FE modelling of roll forming and Chain-die forming the U-channels with same product parameters are introduced in detail in this section. Then the material properties of the working piece adopted in this study are illustrated followed by the clarifications of the contact properties employed between the forming tools and the workpiece.

\section{Simulation set-up.}

The simulation verifications were carried out in ABAQUS/Standard. Specific python scripts were imported to ABAQUS/CAE to complete the FE modelling processes. The implicit solution algorithm is employed to improve the accuracy of results. The forming tools are defined as the rigid shell 
bodies and the workpiece is defined as a deformable body. Taking advantages of symmetry to improve the computing efficiency, only one half of the workpiece and rolls have been modelled.

In FE modelling of the roll forming process, all the base radii of the forming tools are $0.30 \mathrm{~m}$. The center points of the rolls were assigned as the reference rotation points of the corresponding forming tools respectively. The angular velocities, $\omega$, of the rotations of the forming tools were set as the $0.5 \mathrm{rad} / \mathrm{s}$, and in meanwhile the horizontal forward velocity of the working piece , $v$, was set as $15 \mathrm{~mm} / \mathrm{s}(v=\omega r)$. As the main plastic deformation occurs in the bend corners, the initial flat blank had been meshed using different mesh sizes. A very fine mesh has been adopted in the bend corners and flange edge portions and a coarse mesh had been applied in the web of the blank. The workpiece was meshed with 97500 eight node linear brick elements with reduced integration and hourglass control (C3D8R). There were 5 mesh layers (elements) along the thickness direction to guarantee a good convergence. To avoid penetration into the sheet, the mesh type of the forming tools was the four node 3D bilinear rigid quadrilateral element (R3D4).

In FE modelling of Chain-die forming process, the forming tools were part of the rolls with 35 meter radii. A workpiece identical to the one applied in FE modelling of roll forming process was adopted in FE modelling of Chain-die forming process. The same meshing strategies and similar boundaries conditions were applied in the FE model of Chain-die forming process. The details of the FE models of roll forming and Chain-die forming processes and the mesh of the workpiece are shown in Fig.2 (a) and (b) respectively.

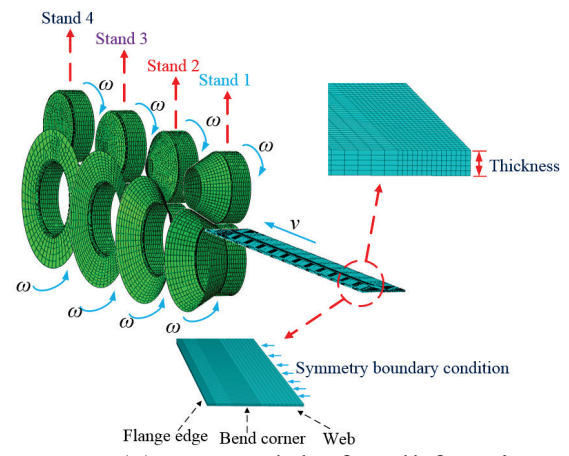

(a) FE model of Roll forming

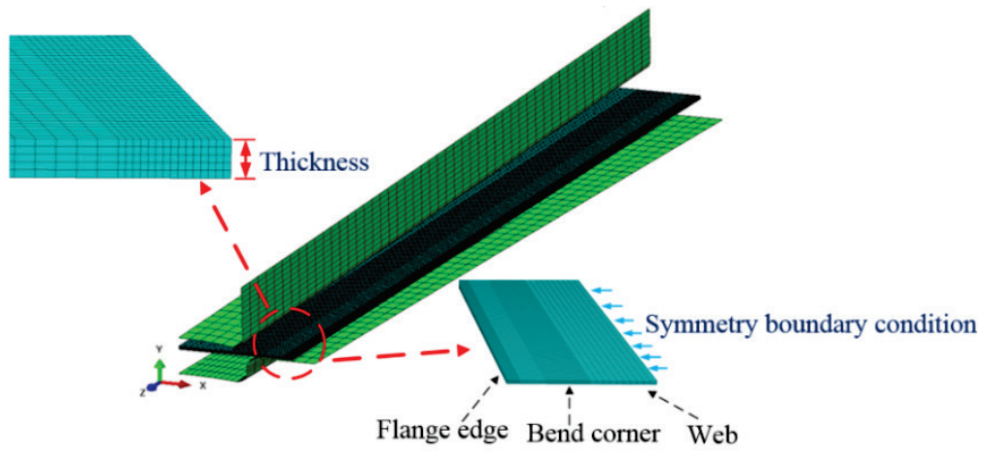

(b) FE model of Chain-die forming

Fig 2.FE models of roll forming and Chain-die forming

\section{Material properties of the workpiece.}

Material used in the FE models is an elastic-plastic strain hardening material. The true plastic stressstrain curve of the sheet metal can be calculated and interpolated using Swift's isotropic strain hardening law, as shown in Eq.1. As isotropic hardening is applied in all simulations, Von Mises yield function is sufficient to describe the yield criteria of the material.

$$
\sigma_{e}=K\left(\varepsilon_{e}+\varepsilon_{0}\right)^{n}
$$

where $\sigma_{e}$ is the equivalent stress, $\varepsilon_{e}$ is the equivalent strain, $\varepsilon_{0}$ is the initial strain, $K$ is the strength coefficient and $n$ is the strain hardening exponent. Those values are given in Table 3.

\section{Contact and friction properties between forming tools and workpiece.}

The types of interaction are set as 'surface-to-surface' (implicit) contacts between the deformable surfaces (sheet metal) and the rigid surfaces (forming tools). The penalty method and the Coulomb friction model are applied to the contact constraints. The friction coefficient of the FE models is assumed as 0.1 . The details of the parameters of the FE models have been summarized in Table 1 . 
Table 1. Summary FEM simulation parameters

\begin{tabular}{ccc}
\hline Simulation Parameters & Chain-die forming & Roll forming \\
\hline Product width $-f(\mathrm{~mm})$ & 80 & 80 \\
Roll radius $(\mathrm{mm})$ & 35000 & 30 \\
Blank thickness $-t(\mathrm{~mm})$ & 1.2 & 1.2 \\
Blank length $-L(\mathrm{~mm})$ & 300 & 300 \\
Tensile strength of blank $-T S$ & $1180 \mathrm{MPa}$ & $1180 \mathrm{MPa}$ \\
(MPa) & Implicit & Implicit \\
Algorithm method & 13050 & 13050 \\
Mesh number $($ blank $)$ & --- & 200 \\
Span space $(\mathrm{mm})$ & 845 & 845 \\
Yield strength $-\sigma_{s}(\mathrm{MPa})$ & 1864 & 1864 \\
Strength coefficient $-K(\mathrm{MPa})$ & 206 & 206 \\
Young's modulus $-E(\mathrm{GPa})$ & 0.3 & 0.3 \\
Poisson's ratio $-v$ & 0.000367 & 0.000367 \\
Initial strain $-\varepsilon_{\mathrm{o}}$ & 0.11 & 0.11 \\
Strain hardening exponent $-n$ & $0.45 \%$ & $0.45 \%$ \\
Elastic Strain & &
\end{tabular}

In the FE model of roll forming and Chain-die forming processes, the whole simulations include the loading and unloading processes. Specifically, the workpiece was firstly pulled into the former followed by being gradually formed to a $U$ channel by the friction forces with the rotations of the forming tools, the same as the real forming process. The accumulated stress-strain of the workpiece starts to be released by springback while the forming tools move away from the workpiece. The workpiece with the last stress-strain state in the previous model is finally imported into a new simulation model with an implicit solution algorithm. The stress-strain of the workpiece is further released by springback until it reaches a steady state in the new FE model.

\section{Results and discussions}

The equivalent residual stresses (Von-Mises) in AHSS U channels induced by roll forming and Chain-die forming are presented and discussed in details in this section. The comparison of the longitudinal strain developments of flange edges of roll formed and Chain-die formed $U$ channels is also clarified to explain the phenomenon.

\section{Equivalent residual stresses comparison.}

The residual stresses in AHSS U-channels induced by roll forming and Chain-die forming are presented in Fig.3 (a) and Fig.3 (b) respectively. As shown in Fig.3 (b), the residual stresses in nondeformation areas of Chain-die formed U-channels are negligible while there are significant and uneven residual stresses distribution in non-deformation areas of roll formed AHSS channels.

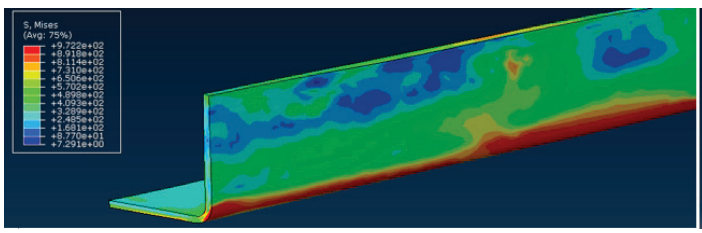

(a) Roll formed U-channels

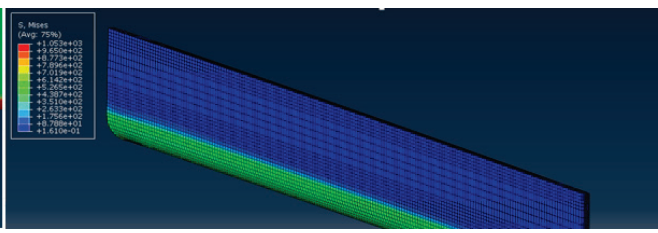

(b) Chain-die formed U-channels

Fig 3.Equivalent residual stresses comparison

As the Chain-die forming process can be considered as a gradually stamping process, there are nearly no redundant deformations in Chain-die forming process. Consequently, the low residual 
stresses in Chain-die formed U-channels are accumulated and the product defects induced in roll forming process can therefore be avoided, as seen in Fig.4.

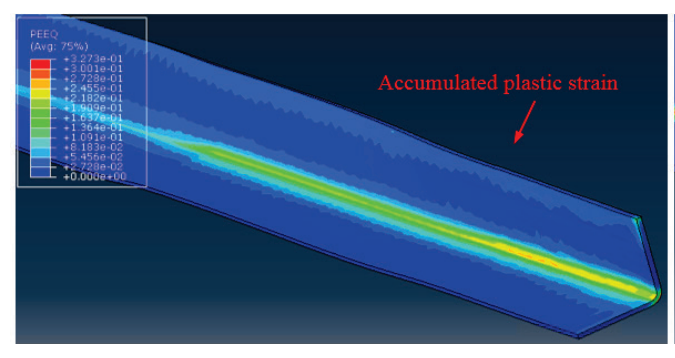

(a) Roll formed U channels

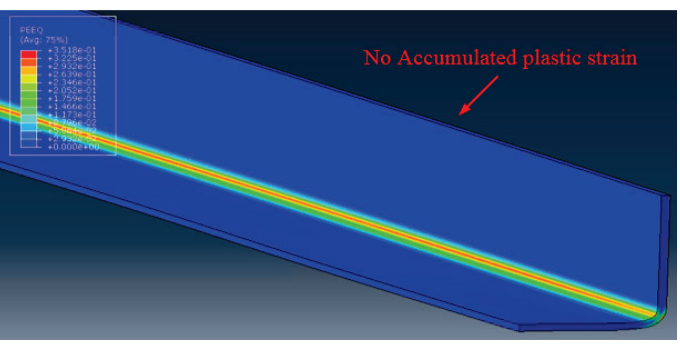

(b) Chain-die formed U channels

Fig 4.Equivalent residual plastic strain comparison (PEEQ)

\section{Longitudinal residual strains comparison.}

As the longitudinal strain development indicates the severity of the relevant forming process, it can be used to explain the characteristic differences of the residual stress distributions in two types of AHSS U-channels. The comparison of the longitudinal strain developments of flange edges of Chaindie formed and roll formed the AHSS U-channels is shown in Fig.5. It is found that the longitudinal strain developed during Chain-die forming is much smoother, the peak strain and residual strain are smaller than in roll forming, even just in one forming pass rather than 4 passes of roll forming. The unavoidable redundant plastic deformation in a roll forming process can also be avoided in Chain-die forming.

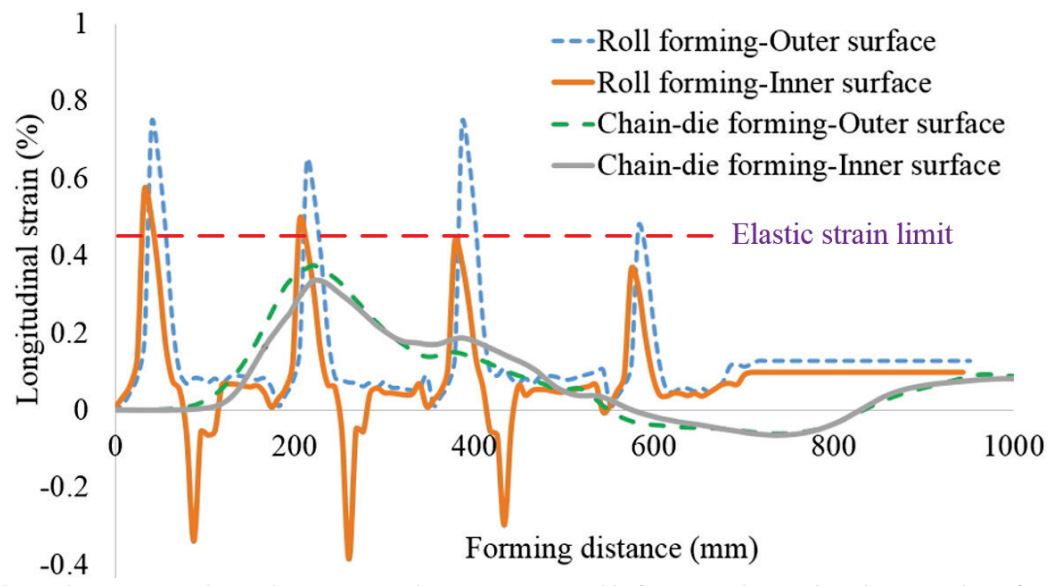

Fig 5.The longitudinal strain development between roll formed and Chain-die formed Uchannels

As shown as in Fig.5, the peak longitudinal strain in the roll forming process is nearly 2 times larger than that in the Chain-die forming process. It should be noted that the bending on the flange phenomenon in Chain-die forming is much lighter and gentler than in roll forming, the corresponding bending strain is much smaller than in roll forming. That is, the surface longitudinal strain superposing the membrane strain and bending strain on the flange during Chain-die forming is well below the material's elastic limit but not in roll forming. It is therefore hard to predict and control the quality of a roll formed product due to its complicated longitudinal strain development. On the contrary, it is possible to make a product with zero residual stress in the non-deformed area by Chain-die forming and give a better quality product than in roll forming. 


\section{Concluding Remarks}

The residual stresses in Chain-die formed AHHS U-channels are investigated numerically in this paper. Finite element analysis is employed to simulate the roll forming and Chain-die forming processes. The equivalent residual stresses of the roll formed and Chain-die formed products are discussed. Experimental investigation of the residual stresses in Chain-die formed U-channels is very necessary to verify the simulations. Some conclusions are reached by this study:

- Using Chain-die forming can achieve much more bending without product defects than roll forming in a single pass. Hence Chain-die forming can maximally reserve the material's ductility;

- Unlike the high residual stresses distribution in the non-deformation areas in roll formed Uchannels, the low redundant strains accumulated in Chain-die formed forming makes the residual stresses in U-channels well below the corresponding material's yield point;

- It is hard to predict the residual stresses in roll formed product due to its complicated fabrication processes, including bending, reverse bending and other unnecessary deformation types. On the contrary, it is possible to make a product with zero residual stress in the nondeformed area by Chain-die forming and that gives a better quality product than in roll forming.

The determination of residual stresses in Chain-die formed U-channels by the neutron diffraction method is currently in progress and the experiments are supported by Bragg Institute beam time proposal 4865. The experimental verification of the numerical simulations will be presented in a future paper.

\section{Acknowledgement}

The authors would like to thank for the financial support from the Baosteel-Australia Joint Research and Development Centre (BAJC), Ningbo SaiRolf Metal Forming Co., Ltd., Bragg Institute beam time proposal 4865 and China Scholarship Council. Colleagues who contributed their efforts and support to this paper are also appreciated. Finally, the authors would like to give special thanks to Baosteel Co.,Ltd. for providing the material properties of the experimental samples.

\section{References}

[1] Paralikas, J., Salonitis, K., Chryssolouris, G., 2009. Investigation of the effects of main rollforming process parameters on quality for a V-section profile from AHSS. The International Journal of Advanced Manufacturing Technology 2009, 44(3-4), 223-237.

http://dx.doi.org/10.1007/s00170-008-1822-9

[2] Panton, S. M.; Zhu, S. D.; Duncan, J. L. Fundamental deformation types and sectional properties in roll forming. International journal of mechanical sciences 1994, 36(8), 725-735. http://dx.doi.org/10.1016/0020-7403(94)90088-4

[3] Semiatin, S.L. ASM Handbook; American Society for Metals: Materials Park, United States, 1988; 2110 pp.

[4] Hou, G., Jing, X., Yan, D., \& Shen, K. Prediction of longitudinal residual stress distribution in cold-formed square hollow sections. In Electric Technology and Civil Engineering (ICETCE), 2011 International Conference on (pp. 557-562). IEEE.

[5] Zhang, Y. Ding, S., 2012. A comparison study of Chain-die Forming and roll forming by forming a top hat section. Proceedings of the 14th International Conference on Metal Forming, Wiley, London, England, 703-706. 